\title{
Wettability alteration and oil recovery by spontaneous imbibition of smart water and surfactants into carbonates
}

\author{
Saeb Ahmadi ${ }^{1} \cdot$ Mostafa Hosseini $^{2} \cdot$ Ebrahim Tangestani $^{3} \cdot$ Seyyed Ebrahim Mousavi ${ }^{3} \cdot$ Mohammad Niazi $^{3}$
}

Received: 3 March 2019 / Published online: 2 January 2020

(c) The Author(s) 2020

\begin{abstract}
Naturally fractured carbonate reservoirs have very low oil recovery efficiency owing to their wettability and tightness of matrix. However, smart water can enhance oil recovery by changing the wettability of the carbonate rock surface from oilwet to water-wet, and the addition of surfactants can also change surface wettability. In the present study, the effects of a solution of modified seawater with some surfactants, namely $\mathrm{C}_{12} \mathrm{TAB}$, SDS, and TritonX-100 (TX-100), on the wettability of carbonate rock were investigated through contact angle measurements. Oil recovery was studied using spontaneous imbibition tests at 25,70 , and $90^{\circ} \mathrm{C}$, followed by thermal gravity analysis to measure the amount of adsorbed material on the carbonate surface. The results indicated that $\mathrm{Ca}^{2+}, \mathrm{Mg}^{2+}$, and $\mathrm{SO}_{4}{ }^{2-}$ ions may alter the carbonate rock wettability from oil-wet to water-wet, with further water wettability obtained at higher concentrations of the ions in modified seawater. Removal of $\mathrm{NaCl}$ from the imbibing fluid resulted in a reduced contact angle and significantly enhanced oil recovery. Low oil recoveries were obtained with modified seawater at 25 and $70{ }^{\circ} \mathrm{C}$, but once the temperature was increased to $90{ }^{\circ} \mathrm{C}$, the oil recovery in the spontaneous imbibition experiment increased dramatically. Application of smart water with $\mathrm{C}_{12} \mathrm{TAB}$ surfactant at $0.1 \mathrm{wt} \%$ changed the contact angle from $161^{\circ}$ to $52^{\circ}$ and enhanced oil recovery to $72 \%$, while the presence of the anionic surfactant SDS at $0.1 \mathrm{wt} \%$ in the smart water increased oil recovery to $64.5 \%$. The TGA analysis results indicated that the adsorbed materials on the carbonate surface were minimal for the solution containing seawater with $\mathrm{C}_{12} \mathrm{TAB}$ at $0.1 \mathrm{wt} \%$ ( $\mathrm{SW}+\mathrm{CTAB}$ $(0.1 \mathrm{wt} \%))$. Based on the experimental results, a mechanism was proposed for wettability alteration of carbonate rocks using smart water with SDS and $\mathrm{C}_{12} \mathrm{TAB}$ surfactants.
\end{abstract}

Keywords Smart water $\cdot$ Surfactants $\cdot$ Carbonate rock $\cdot$ Wettability alteration

\section{Introduction}

Some half of all oil reservoirs in the world are composed of fractured carbonate rocks which contain more than half of the remaining oil in the world. The most significant challenge faced in producing oil from reservoirs, which ends up reducing the oil recovery factor, is the trapping of large

Edited by Yan-Hua Sun

Saeb Ahmadi

Saeb.ahmadi@gmail.com

1 Department of Chemical Engineering Sanandaj Branch, Islamic Azad University, Sanandaj, Iran

2 Department of Petroleum Engineering, Faculty of Chemical Engineering, Tarbiat Modares University, Tehran, Iran

3 Faculty of Chemical Engineering, Tarbiat Modares University, Tehran, Iran amounts of oil within the rock matrix and adhesion of the oil to the rock surface (Treiber and Owens 1972; Chilingar and Yen 1983; Cuiec 1984). Wettability alteration of calcite surfaces from water-wet to oil-wet may occur due to adsorption of polar components of crude oil, particularly carboxylate molecules, onto the surface of carbonate rock. Neutral-to-oil-wet states of carbonate reservoirs are due to the adsorption of carboxylate components of crude oil on the calcite surface (Anderson 1986; Dubey and Waxman 1991).

Due to the high permeability of the fracture network compared to the rock matrix, the existing oil within the fractures is withdrawn rapidly, during oil displacement by water, while large volumes of oil remain within the rock matrix. One of the main oil production mechanisms in fractured carbonate reservoirs is the spontaneous imbibition mechanism. However, the oil-wet nature of the rock matrix hinders the effectivity of this mechanism, leaving large amounts of oil within the rock matrix (Saidi 1987; Standnes and Austad 
2000a). As a result, any process which can alter wettability of the rock matrix to water-wet will be recognized as an effective approach to enhanced oil recovery (EOR) from fractured carbonate reservoirs. One of the most commonly applied novel EOR techniques for fractured carbonate reservoirs is smart water injection and many researchers have shown the positive effect of this method for improving oil recovery (Ebrahim et al. 2019; Park et al. 2018). The chemical treatment of the injected water was first introduced by Bernard in 1967 but it failed to gain much attention. More serious studies of this topic started later on, in 1990, when the results of research by Wyoming University were published. Researchers from British Petroleum coined the term low-salinity water, while those from Shell adopted the term designed water to describe this technique. Nevertheless, smart water is a general term which encompasses all of such methods. Results from the previous research indicate that the use of smart water and several surfactants can alter carbonate rock wettability from oil-wet to water-wet to enhance oil recovery (Strand et al. 2008, 2016; Fathi et al. 2010; Yi and Sarma 2012; Puntervold et al. 2015; Pal et al. 2018). A study by Strand et al. (2008) showed that the $\mathrm{Ca}^{2+}$, $\mathrm{Mg}^{2+}$, and $\mathrm{SO}_{4}{ }^{2-}$ ions in seawater can enhance oil recovery in chalk rocks (Strand et al. 2008). They reported the change in wettability of the chalk rocks as the main reason behind the enhanced oil recovery. Fathi et al. (2010) found that not only do the concentrations of the active ions $\left(\mathrm{Ca}^{2+}, \mathrm{Mg}^{2+}\right.$, and $\mathrm{SO}_{4}{ }^{2-}$ ) contribute to oil recovery, but also $\mathrm{NaCl}$ content affects this process, so that an increase in $\mathrm{NaCl}$ content reduces oil recovery. Puntervold et al. (2015) observed that with removing the $\mathrm{NaCl}$ salt and increasing the concentration of $\mathrm{SO}_{4}{ }^{2-}$ ions in modified seawater, oil recovery was enhanced significantly in spontaneous imbibition experiments at $90{ }^{\circ} \mathrm{C}$.

Zahid et al. (2012) investigated the effect of flooding with smart water of high salinity on oil recovery in Stevns Klint chalk cores. Their results indicated enhanced oil recovery using high-salinity seawater for all three samples of North Sea, Latin America, and Middle Eastern crude. Standnes and Austad (2000b) suggested that cationic surfactants have large impacts in altering carbonate rock wettability toward water-wet conditions, thus enhancing oil recovery. The mechanisms proposed for wettability alteration of carbonates to water wetness include the formation of a pair of ions between the surfactant and fatty acids adsorbed on the rock surface. Jarrahian et al. (2012) studied the effects of three surfactants, cationic, anionic, and nonionic, on the wettability state of dolomitic rock. Their results showed that the cationic surfactant imposed larger effects in changing wettability. Their proposed mechanism for the alteration of the wettability with the cationic surfactant, $\mathrm{C}_{12} \mathrm{TAB}$, was ionic interaction between the surfactant and fatty acid adsorbed on the rock surface. Karimi et al. (2016) investigated the effect of a cationic surfactant along with $\mathrm{Mg}^{2+}$ and $\mathrm{SO}_{4}{ }^{2-}$ ions on oil recovery, using spontaneous imbibition tests. Their findings indicated that a combination of a cationic surfactant along with the potential determining ions can induce a greater increase in oil recovery in spontaneous imbibition tests. From the results of the previous research, it can be understood that surfactants can contribute to changed wettability and enhanced oil recovery from carbonate reservoirs (Saidi 1987; Yi and Sarma 2012). For field applications, however, large amounts of these expensive chemicals are required. Thus, for economic reasons, oil companies are reluctant to employ these materials in field applications, so that the use of low-cost methods has gained a large deal of attention. Therefore, it seems that a combination of smart water with low amounts of surfactants represents a feasible injection fluid on field scale. The present research investigates the effect of the mixture of smart water with three surfactants: $\mathrm{C}_{12} \mathrm{TAB}, \mathrm{SDS}$, and TX-100 on wettability state and oil recovery from carbonate reservoirs, using contact angle measurements, spontaneous imbibition tests, and TGA analysis.

\section{Experimental}

\subsection{Solid phase}

Carbonate reservoir rock from an oil field in south Iran was used in contact angle measurement tests, spontaneous imbibition experiments, and TGA analysis. For the spontaneous imbibition tests, $55-\mathrm{cm}$-long cores with a diameter of $37 \mathrm{~mm}$ were used, while slices of $37 \mathrm{~mm}$ in diameter and $2 \mathrm{~mm}$ in thickness were used for the contact angle measurement tests. Properties of core plugs used in this study are shown in Table 1.

\subsection{Oil phase}

Crude oil used was from an oil field in the south of Iran, with a total acid number (TAN) of $0.38 \mathrm{mg} \mathrm{KOH} / \mathrm{g}$ oil. Prior to use, the crude sample was centrifuged and then filtered through a $5 \mu \mathrm{m}$ millipore filter to remove any impurities.

\subsection{Brines}

The salts and surfactants used to prepare the brines were from Merck Co., with purities beyond 99\%. The brines used are given in Table 2. The terminology used in this study is as follows: SW is synthetic seawater (base brine); SW0Mg is SW without $\mathrm{Mg}^{2+}$; $\mathrm{SW} 3 \mathrm{Mg}$ is SW with 3 times the $\mathrm{Mg}^{2+}$ concentration in SW; SW0Ca is SW without $\mathrm{Ca}^{2+}$; SW3Ca is SW with 3 times the $\mathrm{Ca}^{2+}$ concentration in SW; SW0S is SW without $\mathrm{SO}_{4}{ }^{2-}$; SW3S is SW with 3 
Table 1 Properties of core plugs

\begin{tabular}{|c|c|c|c|c|}
\hline Core plug No. & Brine & Porosity, $\%$ & Permeability, mD & $\begin{array}{l}\text { Initial oil } \\
\text { saturation } \\
S_{\text {oi }}, \%\end{array}$ \\
\hline 1 & FW & 17.9 & 2.48 & 80 \\
\hline 2 & SW & 18.0 & 2.46 & 80 \\
\hline 3 & SW0Mg & 18.0 & 2.50 & 82 \\
\hline 4 & SW3Mg & 18.1 & 2.50 & 81 \\
\hline 5 & SW0Ca & 18.0 & 2.50 & 81 \\
\hline 6 & SW3Ca & 17.9 & 2.50 & 80 \\
\hline 7 & SW0S & 18.0 & 2.50 & 80 \\
\hline 8 & SW3S & 18.0 & 2.50 & 81 \\
\hline 9 & SW0NaCl & 18.1 & 2.52 & 82 \\
\hline 10 & $\mathrm{SW} 3 \mathrm{NaCl}$ & 18.1 & 2.48 & 82 \\
\hline 11 & $\mathrm{SW}+0.05 \mathrm{wt} \% \mathrm{CTAB}$ & 18.0 & 2.49 & 80 \\
\hline 12 & $\mathrm{SW}+0.10 \mathrm{wt} \% \mathrm{CTAB}$ & 18.1 & 2.50 & 81 \\
\hline 13 & $\mathrm{SW}+0.05 \mathrm{wt} \% \mathrm{SDS}$ & 18.1 & 2.50 & 82 \\
\hline 14 & $\mathrm{SW}+0.10 \mathrm{wt} \% \mathrm{SDS}$ & 18.0 & 2.48 & 81 \\
\hline 15 & $\mathrm{SW}+0.05 \mathrm{wt} \% \mathrm{TX}-100$ & 18.0 & 2.50 & 82 \\
\hline 16 & $\mathrm{SW}+0.10 \mathrm{wt} \% \mathrm{TX}-100$ & 18.0 & 2.50 & 80 \\
\hline
\end{tabular}

Table 2 Brine compositions

\begin{tabular}{|c|c|c|c|c|c|c|c|c|c|c|c|}
\hline \multirow[t]{2}{*}{ Solution No. } & \multirow[t]{2}{*}{ Brine } & \multicolumn{6}{|c|}{ Ion concentration, $\mathrm{mol} / \mathrm{L}$} & \multirow[t]{2}{*}{ CTAB, wt $\%$} & \multirow[t]{2}{*}{ SDS, wt $\%$} & \multirow[t]{2}{*}{ TX-100, wt $\%$} & \multirow[t]{2}{*}{ TDS, g/L } \\
\hline & & $\mathrm{Mg}^{2+}$ & $\mathrm{Ca}^{2+}$ & $\mathrm{SO}_{4}{ }^{2-}$ & $\mathrm{Na}^{+}$ & $\mathrm{HCO}_{3}^{-}$ & $\mathrm{Cl}^{-}$ & & & & \\
\hline 1 & FW & 0.076 & 0.437 & 0.000 & 2.620 & 0.003 & 3.643 & 0.000 & 0.000 & 0.000 & 208.732 \\
\hline 2 & SW & 0.073 & 0.012 & 0.033 & 0.5525 & 0.002 & 0.6545 & 0.000 & 0.000 & 0.000 & 41.4207 \\
\hline 3 & SWOMg & 0 & 0.012 & 0.033 & 0.5525 & 0.002 & 0.5085 & 0.000 & 0.000 & 0.000 & 34.4784 \\
\hline 4 & SW3Mg & 0.219 & 0.012 & 0.033 & 0.5525 & 0.002 & 0.9465 & 0.000 & 0.000 & 0.000 & 55.3053 \\
\hline 5 & SW0Ca & 0.073 & 0 & 0.033 & 0.5525 & 0.002 & 0.6305 & 0.000 & 0.000 & 0.000 & 40.0911 \\
\hline 6 & $\mathrm{SW} 3 \mathrm{Ca}$ & 0.073 & 0.036 & 0.033 & 0.5525 & 0.002 & 0.7025 & 0.000 & 0.000 & 0.000 & 44.0799 \\
\hline 7 & SW0S & 0.073 & 0.012 & 0 & 0.5360 & 0.002 & 0.6545 & 0.000 & 0.000 & 0.000 & 36.7347 \\
\hline 8 & SW3S & 0.073 & 0.012 & 0.099 & 0.5855 & 0.002 & 0.7205 & 0.000 & 0.000 & 0.000 & 54.6471 \\
\hline 9 & $\mathrm{SW} 0 \mathrm{NaCl}$ & 0.073 & 0.012 & 0.033 & 0.068 & 0.002 & 0.17 & 0.000 & 0.000 & 0.000 & 13.1259 \\
\hline 10 & $\mathrm{SW} 3 \mathrm{NaCl}$ & 0.073 & 0.012 & 0.033 & 1.5215 & 0.002 & 1.6295 & 0.000 & 0.000 & 0.000 & 98.3607 \\
\hline 11 & $\mathrm{SW}+0.05 \mathrm{wt} \% \mathrm{CTAB}$ & 0.073 & 0.012 & 0.033 & 0.5525 & 0.002 & 0.6545 & 0.050 & 0.000 & 0.000 & 41.4207 \\
\hline 12 & $\mathrm{SW}+0.10 \mathrm{wt} \% \mathrm{CTAB}$ & 0.073 & 0.012 & 0.033 & 0.5525 & 0.002 & 0.6545 & 0.100 & 0.000 & 0.000 & 41.4207 \\
\hline 13 & $\mathrm{SW}+0.05 \mathrm{wt} \% \mathrm{SDS}$ & 0.073 & 0.012 & 0.033 & 0.5525 & 0.002 & 0.6545 & 0.000 & 0.050 & 0.000 & 41.4207 \\
\hline 14 & $\mathrm{SW}+0.10 \mathrm{wt} \% \mathrm{SDS}$ & 0.073 & 0.012 & 0.033 & 0.5525 & 0.002 & 0.6545 & 0.000 & 0.100 & 0.000 & 41.4207 \\
\hline 15 & $\mathrm{SW}+0.05 \mathrm{wt} \% \mathrm{TX}-100$ & 0.073 & 0.012 & 0.033 & 0.5525 & 0.002 & 0.6545 & 0.000 & 0.000 & 0.050 & 41.4207 \\
\hline 16 & $\mathrm{SW}+0.10 \mathrm{wt} \% \mathrm{TX}-100$ & 0.073 & 0.012 & 0.033 & 0.5525 & 0.002 & 0.6545 & 0.000 & 0.000 & 0.01 & 41.4207 \\
\hline
\end{tabular}

times the $\mathrm{SO}_{4}{ }^{2-}$ concentration in $\mathrm{SW}, \mathrm{SW} 0 \mathrm{NaCl}$ is $\mathrm{SW}$ without $\mathrm{Na}^{+}$and $\mathrm{Cl}^{-}$; and $\mathrm{SW} 3 \mathrm{NaCl}$ is $\mathrm{SW}$ spiked 3 times with $\mathrm{NaCl}$.
In addition, other solutions were prepared with seawater along with different weight percentages of $\mathrm{C}_{12} \mathrm{TAB}, \mathrm{SDS}$, and TX-100 surfactants. 
Moreover, solutions 11-16 were prepared using seawater along with different weight percentages of $\mathrm{C}_{12} \mathrm{TAB}$, SDS, and TX-100 surfactants.

\subsection{Carbonate surface treatment}

First of all, the rock samples were washed with a solution of toluene and methanol at 1:1 ratio. The slices prepared for the contact angle tests were immersed in formation water (FW) at $90{ }^{\circ} \mathrm{C}$ for $2 \mathrm{~h}$, to form a film of brine on the rock surface. The slices were then aged in crude oil at $90{ }^{\circ} \mathrm{C}$ for 4 weeks. After this, the samples were washed with distilled water to remove excess crude oil on the rock surface, and finally dried at $25{ }^{\circ} \mathrm{C}$. In order to investigate the effects of the solutions of modified seawater and surfactants on wettability of the carbonate surfaces, the aged samples were placed in the wettability modifier solutions at $90{ }^{\circ} \mathrm{C}$ for $48 \mathrm{~h}$ to conduct the contact angle test.

\subsection{Contact angle measurement}

The contact angle test is a common method for determining the wettability state of different surfaces. In order to measure contact angle, the oil-wetted rock sample was immersed in FW. Then, a crude oil drop was placed on the rock surface from below (see Fig. 1). Contact angle measurements were performed at room temperature and atmospheric pressure using a DSA 100 KRUSS apparatus (Kruss, Hamburg, Germany) with an accuracy of $\pm 0.1^{\circ}$.

\subsection{Preparing the cores for spontaneous imbibition tests}

Clean cores were vacuumed using a vacuum pump and a desiccator. The cores were then saturated with the FW under vacuum. Following the injection of the FW, crude oil was injected into the core using a core flooding apparatus until irreducible water saturation was reached. Finally, the cores were aged at $90{ }^{\circ} \mathrm{C}$ for 4 weeks.

\subsection{Spontaneous imbibition}

In order to undertake imbibition tests, glass-made Amott cells of high temperature tolerance (up to $500{ }^{\circ} \mathrm{C}$ ) were used. The cell cap sealing was performed using silicon adhesive. Next, the aged cores were exposed to the imbibing fluid. Spontaneous imbibition tests were conducted at 25,70 , and $90{ }^{\circ} \mathrm{C}$, where the volume of produced oil was recorded as a function of time.

\subsection{Thermogravimetric analysis (TGA)}

In this analysis, the changes in the mass of a solid sample with increasing temperature, representing the amounts of adsorbed matter on the surface of the solid, were measured. For this purpose, the solutions that had the most influence on the wettability, according to the contact angle test, were selected for the TGA test. The powdered rock was aged at $90{ }^{\circ} \mathrm{C}$ for 4 weeks, then washed with distilled water and dried at ambient temperature and finally placed in the wettability modifier solutions for $48 \mathrm{~h}$ at $90{ }^{\circ} \mathrm{C}$. The amount of oil and brine used for TGA was $100 \mathrm{~mL}$ for all samples.

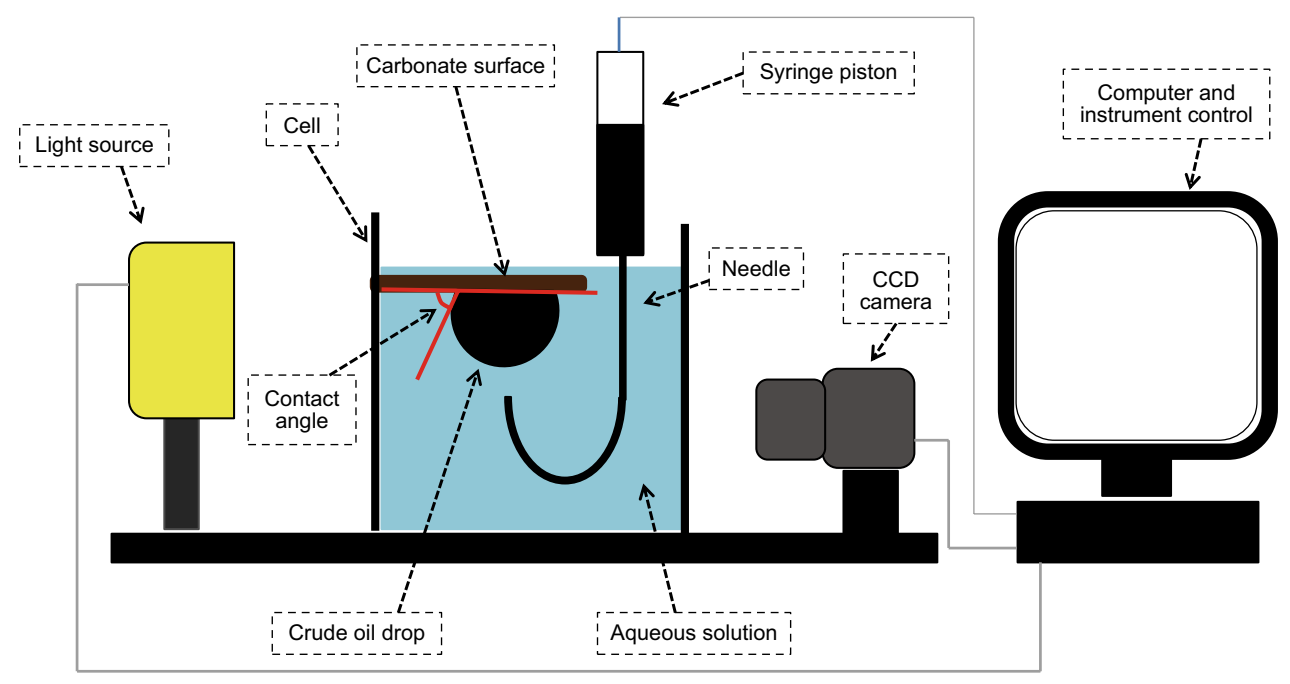

Fig. 1 Schematic diagram of the contact angle measurement device 
Powdered carbonate rock of $4 \mathrm{mg}$ was heated continuously in an aluminum vessel (under a flow of argon) to $600{ }^{\circ} \mathrm{C}$, at a heating rate of $10{ }^{\circ} \mathrm{C} / \mathrm{min}$, while the sample weight loss, representing the amounts of adsorbed matter on the surface of the solid, was measured as a function of temperature. The thermogravimetric analyzer PL-STA was used in this study.

\section{Results and discussion}

\subsection{Contact angle measurements}

Following the aging of carbonate surfaces in crude oil, the surface wettability state changed to oil-wet, for which the average contact angle was equal to $159^{\circ}$. Figure 2 shows the oil drop on the carbonate surface before and after aging in crude oil, with measured contact angles of $31^{\circ}$ and $161^{\circ}$, respectively. The change in this angle indicates that the carbonate surface has become oil-wet in the aging process, due to the adsorption of the existing carboxylic acids in the crude oil on the carbonate surface.

The results shown in Fig. 3 indicate that the seawater (SW) sample succeeded in reducing the contact angle of the rock to $98^{\circ}$, establishing a good efficiency of this solution in changing wettability of the carbonate rock surface. However, the FW (formation water) solution failed to impose any significant effect on the wettability alteration of the carbonate rock. An increase in the concentration of $\mathrm{Mg}^{2+}$ ions in the smart water resulted in further reduction in the contact angle, while their complete elimination ended up by increasing the contact angle of the carbonate surface. A similar trend was observed with the increase in the concentration of $\mathrm{Ca}^{2+}$ ions. However, the effect of $\mathrm{Mg}^{2+}$ ions on wettability change exceeded that of $\mathrm{Ca}^{2+}$ ions, which was attributed to the higher charge density of the $\mathrm{Mg}^{2+}$ ion with respect to the $\mathrm{Ca}^{2+}$ ion. The greatest

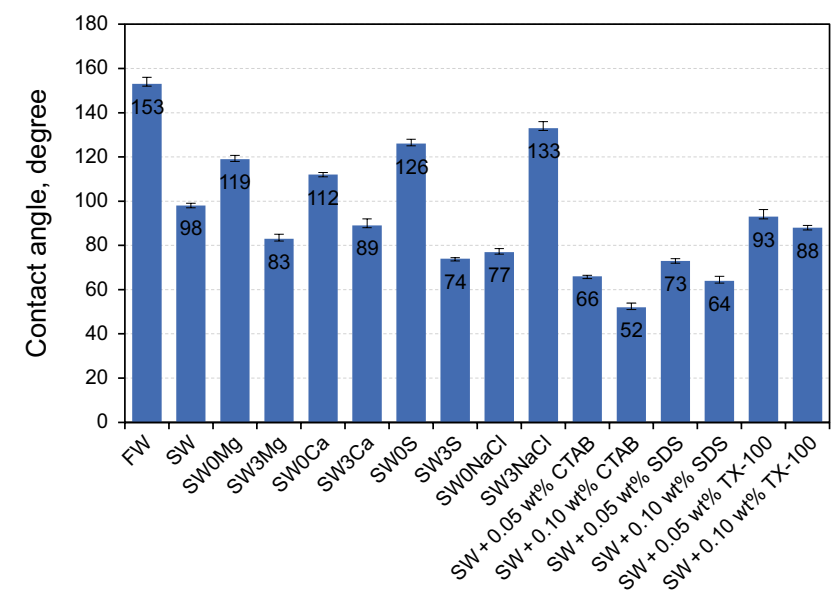

Fig. 3 Contact angles of carbonate surfaces after being treated with smart water and surfactant solutions

reduction in contact angle was observed when increasing the concentration of $\mathrm{SO}_{4}{ }^{2-}$ in the smart water. In contrast, an increase in the concentration of $\mathrm{NaCl}$ salt was associated with negative impacts and increased the contact angle compared to that obtained with seawater. The results of contact angle tests on carbonate rock resembled those reported in the previous research on chalk rock, so that one can suggest that the dominant governing mechanism in this process is similar to that in the chalk rock (Strand et al. 2008; Fathi et al. 2010; Fernø et al. 2011; Zahid et al. 2012).

As was mentioned before, the main cause of the change in wettability of the carbonate rock surface is adsorption of carboxylic acids in the crude oil onto the rock surface; being negatively charged, these acids were adsorbed by cations. The mechanism through which smart water works to change wettability is as follows: an increase in the concentration of $\mathrm{SO}_{4}^{2-}$ ions in the wettability treatment solution reduces
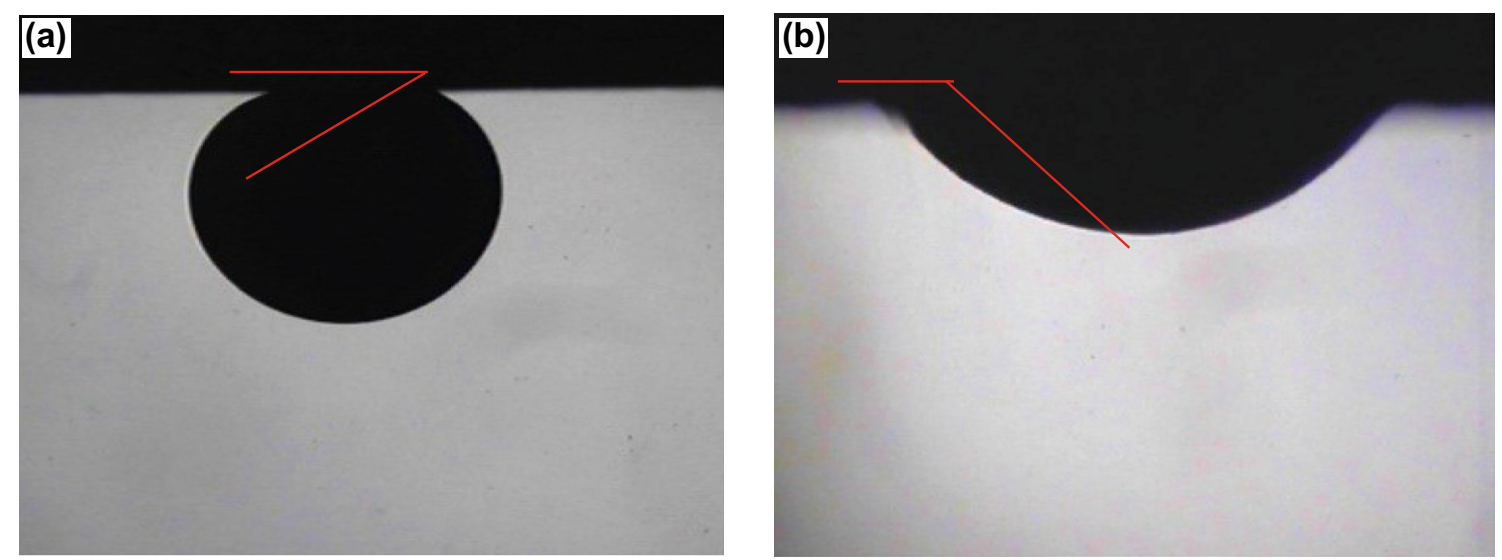

Fig. 2 Oil drop on the carbonate surface. a Before aging in crude oil. b After aging in crude oil 
the positive charge on the surface of the carbonate rock and enhances the capacity of divalent cations to dissociate the carboxylic acids on the rock surface. Accordingly, with an increase in concentration of sulfate ions in smart water, the contact angle decreases considerably. An increase in the concentration of divalent cations boosts their activity and efficiency in dissociating the adsorbed carboxylic acids on rock surface, while an increase in the concentration of $\mathrm{NaCl}$ attenuates the activity of divalent ions and hinders their access to adsorbed carboxylic acids on water-wetted surfaces; therefore, the activity of the effective ions is reduced, while the contact angle increases. As can be observed, by introducing a small amount of the cationic surfactant, the contact angle reduced considerably. The addition of the anionic surfactant (SDS) to the smart water also resulted in a significant reduction in contact angle. However, when mixed with the smart water solution, the nonionic surfactant (TX-100) failed to produce significant effects on contact angle and wettability mode. Karimi et al. (2015) showed that adding a small amount of the cationic surfactant DTAB to the wettability modifier solution results in a significant decrease in contact angle and an increase in oil recovery, which is in agreement with our results. Moreover, Jarrahian et al. (2012) observed that the surfactant $\mathrm{C}_{12} \mathrm{TAB}$ made a significant contribution to change the wettability of a calcite surface, compared to SDS and TX-100. The mechanism of wettability alteration with increasing concentration of CTAB in smart water solution $(\mathrm{SW}+\mathrm{CTAB})$ was similar to the mechanism involved when increasing the concentration of divalent cations in the smart water solution, which dissociate adsorbed carboxylic acids on the rock surface by their positive charges, increasing the water wetness of the surface. The use of the anionic surfactant SDS separately brings about no significant change in carbonate rock wettability (Jarrahian et al. 2012), but once mixed with the smart water solution, SDS reduced the positive charge on the rock surface, thereby enhancing the access of divalent cations to the surface of the carbonate rock, so that the contact angle decreased considerably. The mechanism through which this surfactant, together with smart water, contributes to changed rock wettability is similar to the mechanism of the $\mathrm{SO}_{4}{ }^{2-}$ ions, which attenuates positive charge of the rock surface by its negative charge. Figure 4 shows the proposed mechanism for changing carbonate rock wettability using a mix of smart water and cationic and anionic ions.

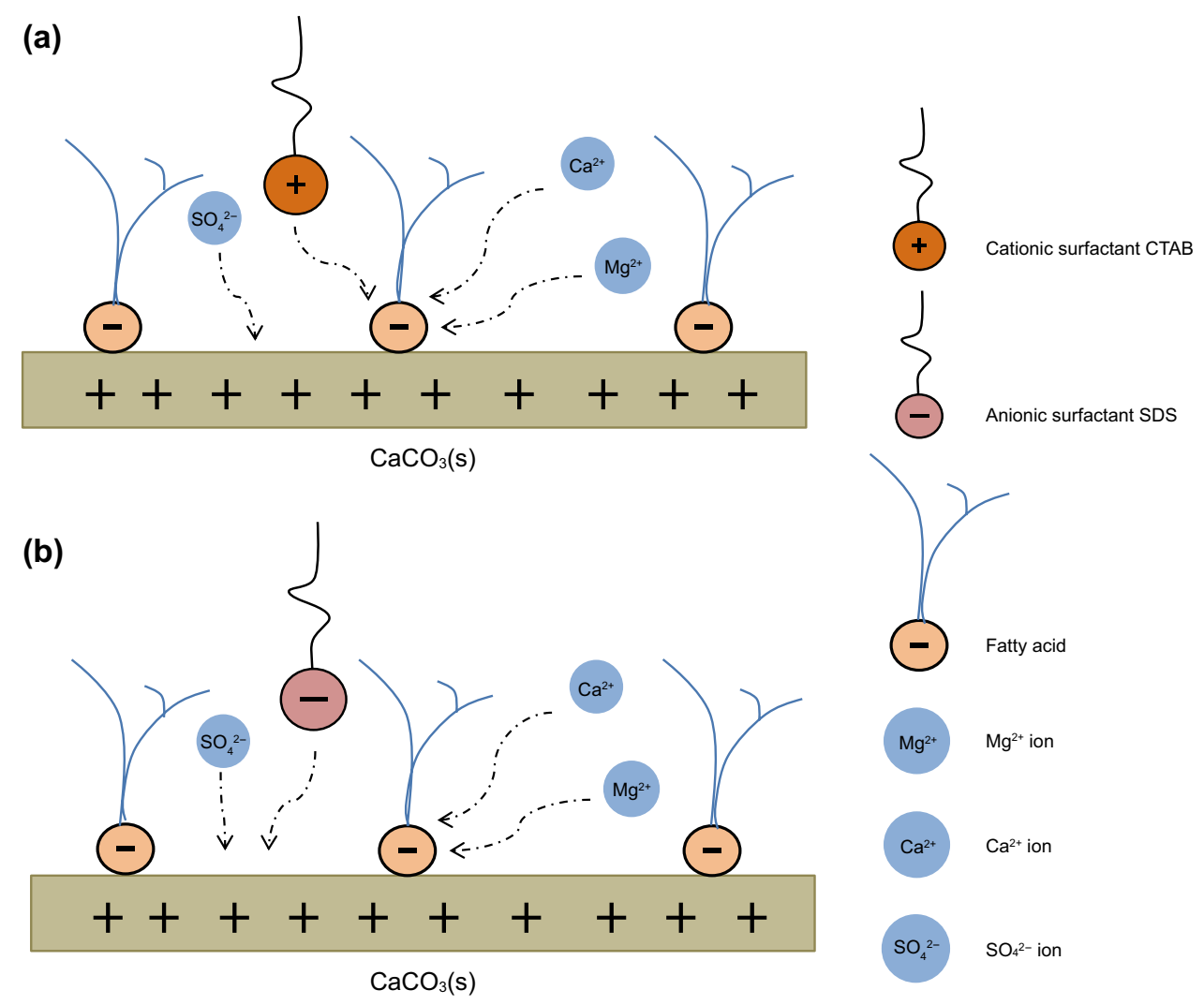

Fig. 4 Proposed mechanism of wettability alteration of carbonate rock surfaces treated by $\mathbf{a}$ SW $+\mathrm{C}_{12} \mathrm{TAB}$ and $\mathbf{b} \mathrm{SW}+\mathrm{SDS}$ 


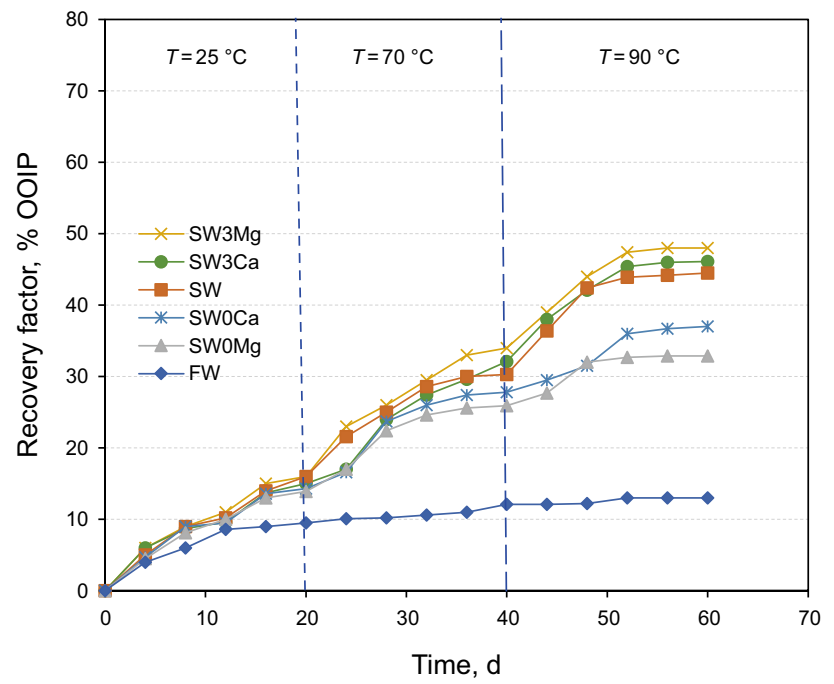

Fig. 5 Oil recovery by spontaneous imbibition into carbonate cores using smart water: effect of divalent cations

\subsection{Oil recovery from spontaneous imbibition experiments}

Spontaneous imbibition tests were performed at 25, 70, and $90{ }^{\circ} \mathrm{C}$ for 60 days. Results of the spontaneous imbibition tests were consistent with the results of the contact angle tests. It seems that the dominant mechanism governing enhanced oil recovery with smart water and surfactant in carbonate rock is the change of wettability from oil-wet to water-wet. The results shown in Fig. 5 show that the use of FW as the imbibing fluid had no significant effect on oil recovery. Moreover, the smart water (SW, SW0Ca, SW0 Mg) enhanced only minor oil recovery at 20 and $70{ }^{\circ} \mathrm{C}$, due to

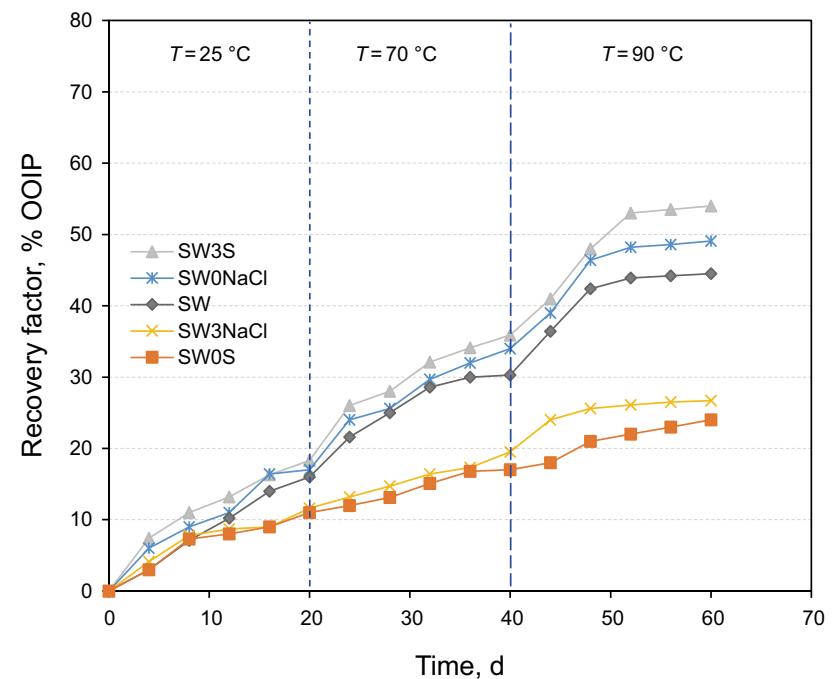

Fig. 6 Oil recovery by spontaneous imbibition into carbonate cores using smart water: effect of $\mathrm{SO}_{4}{ }^{2-}$ and $\mathrm{NaCl}$ the low activity of the ions at these temperatures. However, it increased considerably with the increase in temperature to $90{ }^{\circ} \mathrm{C}$. Strand et al. (2008) also demonstrated enhanced oil recovery from chalk rock at elevated temperatures, due to the higher activity of the ions affecting surface potential. Figure 6 shows that at elevated temperatures, by increasing the concentration of $\mathrm{SO}_{4}{ }^{2-}$ ions, decreasing $\mathrm{NaCl}$ concentration and enhancing the concentration of divalent cations, the oil recovery increased further. Moreover, the use of smart water solution along with the cationic surfactant, $\mathrm{C}_{12} \mathrm{TAB}$, resulted in a significant enhancement in oil recovery, not only at elevated temperatures, but also at lower temperatures, due to the presence of the surfactant (Fig. 7). The highest oil recovery was observed using the smart water solution and cationic surfactant $\mathrm{C}_{12} \mathrm{TAB}$. Furthermore, the solution of seawater and the anionic surfactant, SDS, also increased oil recovery remarkably, with the mechanism of its effect in changing the carbonate rock wettability explained in the previous section.

\subsection{TGA}

The results of the contact angle and spontaneous imbibition tests indicate that wettability change is the main mechanism through which enhanced oil recovery using solutions of smart water with surfactants is achieved, with the reason being the adsorption of carboxylic acids on the rock surface. To further investigate the topic, TGA was used to determine the amount of matter adsorbed on the rock surface. For this purpose, carbonate rock was first aged in oil. It was then treated with smart water and surfactant solutions. The weight loss of the samples versus temperature was

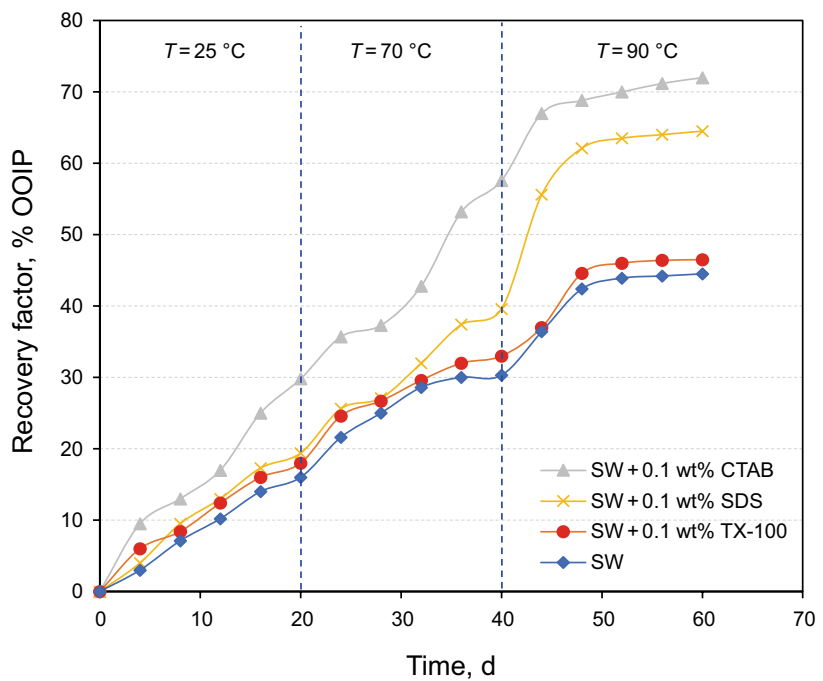

Fig. 7 Oil recovery by spontaneous imbibition into carbonate cores using smart water and surfactants 
investigated in TGA experiments. In this analysis, the weight loss due to rising temperature can be divided into three parts.

Part I-physically adsorbed materials $\left(30-210^{\circ} \mathrm{C}\right)$.

Part II-chemically adsorbed materials (e.g., adsorbed carboxylic acids in crude oil on rock surface) $\left(210-400^{\circ} \mathrm{C}\right)$. Part III-rock decomposition $\left(T>570^{\circ} \mathrm{C}\right)$.

In the TGA test, rock samples that are in contact with wettability modifier solutions have been used. During contact with the solutions used to change the wettability, the majority of oil is separated from the surface and part of the materials that cause carbonate samples to change from more water-wet to oil-wet (fatty acids or carboxylic acids) are chemically absorb on the surface. Samples are washed with distilled water before TGA tests and if there is brine on the sample surface, at this stage or at the first TGA temperature interval $\left(30-210^{\circ} \mathrm{C}\right)$, brine will be removed or evaporated. When the temperature is in a range of 210 to $400{ }^{\circ} \mathrm{C}$, this is related to materials that are chemically absorbed on the surface and remain on the rock. The other oil materials that are not the main effect of changing the wettability of carbonate samples from water-wet to oil-wet in the aging process and are physically absorbed into the rock, are removed from the surface of the rock in contact with the modifier solution, or at the first temperature range in the TGA test.

Figure 8 shows the results of TGA of the carbonate samples treated with smart water solutions ( $\mathrm{SW}, \mathrm{SW} 3 \mathrm{Mg}$, and SW3S). The results indicated that the weight loss was smaller for the sample treated with SW3S compared with those treated with SW3Mg and SW, and the capability of the SW3S solution in removing carboxylic acids exceeded that of the other two solutions ( $\mathrm{SW}$ and SW3Mg). Moreover, TGA tests were further performed on the samples treated

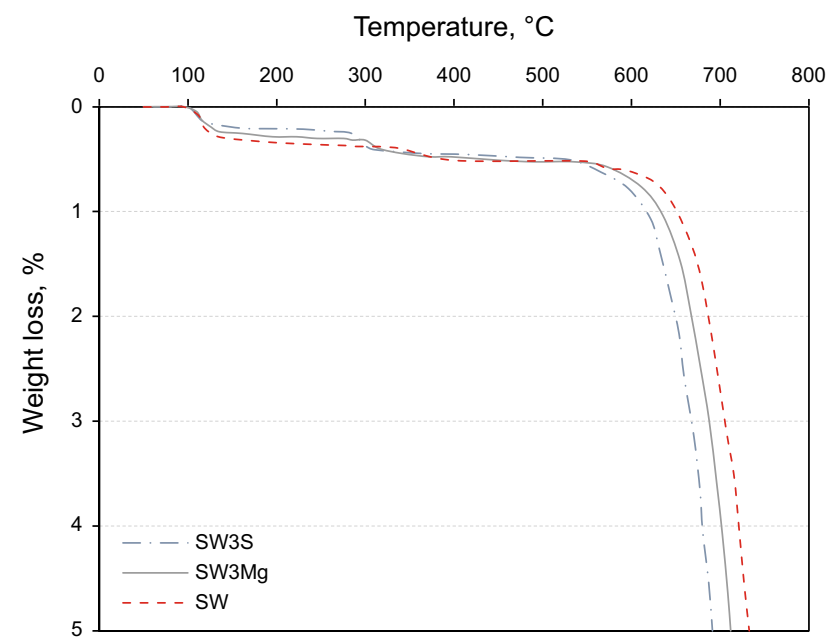

Fig. 8 TGA analysis of oil-wet carbonate samples after being treated with modified seawater: SW3S, SW3Mg, and SW

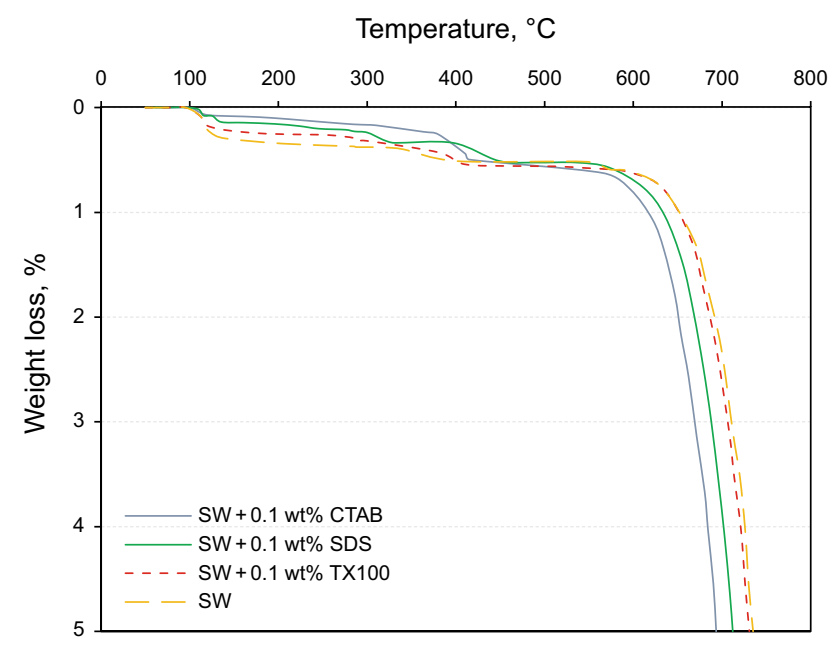

Fig. 9 TGA analysis of oil-wet carbonate samples after being treated with seawater and surfactant solutions

with $\mathrm{SW}+\mathrm{C}_{12} \mathrm{TAB}, \mathrm{SW}+\mathrm{SDS}$ and $\mathrm{SW}+\mathrm{TX}-100$ solutions. Figure 9 shows that the weight loss of the samples treated with $\mathrm{C}_{12} \mathrm{TAB}$ was minimal, indicating the greater capability of the SW + CTAB solution in changing rock wettability and enhancing oil recovery from carbonate cores. The TGA results were consistent with the results of the contact angle and spontaneous imbibition tests, and confirmed that the main cause of oil-wetting of the carbonate surfaces was the adsorption of carboxylic acids in crude oil, with the main mechanism of enhanced oil recovery using the solution of smart water and surfactant being a change of rock surface wettability from oil-wet to water-wet state. Moreover, the results of Jarrahian et al. (2012) also showed that the weight loss was minimal when surfactant $\mathrm{C}_{12} \mathrm{TAB}$ (rather than SDS or TX-100) was used as a calcite surface wettability-treating agent, i.e., $\mathrm{C}_{12} \mathrm{TAB}$ has the largest effect on calcite surface wettability alteration (Jarrahian et al. 2012). Karimi et al. (2015) also observed that the lowest weight loss in TGA analysis was obtained with the calcite surface treated with the cationic surfactant DTAB and $\mathrm{Mg}^{2+}$ ions, indicating the efficiency of this solution in removing the adsorbed fatty acid on the rock surface, which is in agreement with our results.

\section{Conclusions}

The main objective of the present work was to study experimentally the influence of modified seawater solution containing $\mathrm{C}_{12} \mathrm{TAB}$, SDS, and TX-100 surfactants on wettability alteration of carbonate rocks and enhanced oil recovery. Surface wettability change was measured using the contact angle test. The effects of temperature, ionic concentration in seawater, and different surfactants on the recovered oil 
from carbonate cores were investigated through spontaneous imbibition tests. TGA tests were utilized to measure the amount of adsorbed matter on the carbonate rock surface. Finally, a mechanism for carbonate rock wettability alteration using SW + CTAB and SW + SDS solutions was proposed based on the experimental results. The following conclusions can be drawn from the experimental results:

1. The decrease in contact angle using modified smart water solutions, from oil-wet to water-wet is as follows: SW3S $>$ SW0NaCl $>$ SW3Mg $>$ SW3Ca $>$ SW $>$ SW0C a $>$ SWOMg $>$ SWOS $>$ SW $3 \mathrm{NaCl}>$ FW.

2. With increasing concentrations of $\mathrm{SO}_{4}{ }^{2-}$ and $\mathrm{Mg}^{2+}$ ions in the smart water, a further increase in oil recovery from carbonate rock was observed in the spontaneous imbibition test.

3. For the modified seawater solutions, low oil recoveries were obtained at 25 and $70{ }^{\circ} \mathrm{C}$ due to the low activity of the ions. However, increasing the temperature to $90{ }^{\circ} \mathrm{C}$ enhanced oil recovery considerably.

4. The use of cationic surfactant $\mathrm{C}_{12} \mathrm{TAB}$ and anionic surfactant SDS, together with seawater as imbibing fluids, enhanced oil recovery from the carbonate cores, even at low temperatures.

5. The use of cationic surfactant $\mathrm{C}_{12} \mathrm{TAB}$ together with seawater had the largest impact on reducing the contact angle and enhancing oil recovery. A comparison between oil recoveries from the spontaneous imbibition test for the modified seawater solutions containing different surfactants shows that the oil recovery increased in the following order: $\mathrm{SW}+\mathrm{C}_{12} \mathrm{TAB}(0.1 \mathrm{wt} \%)>\mathrm{SW}+\mathrm{SDS}$ $(0.1 \mathrm{wt} \%)>\mathrm{SW}+\mathrm{TX}-100(0.1 \mathrm{wt} \%)>\mathrm{SW}$.

6. The TGA results were in agreement with those of the contact angle and spontaneous imbibition tests, in which the amount of hydrocarbon components adsorbed on the rock surface was lower for the solutions with better effects on wettability change and enhanced oil recovery.

Open Access This article is licensed under a Creative Commons Attribution 4.0 International License, which permits use, sharing, adaptation, distribution and reproduction in any medium or format, as long as you give appropriate credit to the original author(s) and the source, provide a link to the Creative Commons licence, and indicate if changes were made. The images or other third party material in this article are included in the article's Creative Commons licence, unless indicated otherwise in a credit line to the material. If material is not included in the article's Creative Commons licence and your intended use is not permitted by statutory regulation or exceeds the permitted use, you will need to obtain permission directly from the copyright holder. To view a copy of this licence, visit http://creativecommons.org/licenses/by/4.0/.

\section{References}

Anderson WG. Wettability literature survey-part 1: rock/oil/brine interactions and the effects of core handling on wettability. J Pet Technol. 1986;38(10):1125-121144. https://doi.org/10.2118/13932 -PA.

Austad T. Water-based EOR in carbonates and sandstones new chemical understanding of the EOR potential using smart water. Enhanced oil recovery field case studies. Houston: Gulf Professional Publishing; 2013. p. 301-35. https://doi.org/10.1016/B9780-12-386545-8.00013-0.

Chilingar GV, Yen T. Some notes on wettability and relative permeabilities of carbonate reservoir rocks II. Energy Sources. 1983;7(1):67-75. https://doi.org/10.1080/00908318308908076.

Cuiec L. Rock/crude oil interactions and wettability: an attempt to understand their interrelation. In: SPE Annual technical conference and exhibition, Houston, September 16, 1984. https://doi. org/10.2118/13211-MS.

Dubey S, Waxman M. Asphaltene adsorption and desorption from mineral surfaces. SPE Reserv Eng. 1991;6(03):389-95. https:// doi.org/10.2118/18462-PA.

Ebrahim T, Mohsen VS, Mahdi SM, et al. Performance of low salinity water flooding for enhanced oil recovery improved by $\mathrm{SiO}_{2}$ nanoparticles. Pet Sci. 2019;16(2):357-65. https://doi.org/10.1007/ s12182-018-0295-1.

Fathi SJ, Austad T, Strand S. "Smart water" as a wettability modifier in chalk: the effect of salinity and ionic composition. Energy Fuels. 2010;24(4):2514-9. https://doi.org/10.1021/ef901304m.

Fernø M, Grønsdal R, Åsheim J, Nyheim A, Berge M, Graue A. Use of sulfate for water based enhanced oil recovery during spontaneous imbibition in chalk. Energy Fuels. 2011;25(4):1697-706. https:// doi.org/10.1021/ef200136w.

Jarrahian K, Seiedi O, Sheykhan M, Sefti MV, Ayatollahi S. Wettability alteration of carbonate rocks by surfactants: a mechanistic study. Colloids Surf A. 2012;410:1-10. https://doi.org/10.1016/j.colsu rfa.2012.06.007.

Karimi M, Al-Maamari RS, Ayatollahi S, Mehranbod N. Mechanistic study of wettability alteration of oil-wet calcite: the effect of magnesium ions in the presence and absence of cationic surfactant. Colloids Surf A. 2015;482:403-15. https://doi.org/10.1016/j.colsu rfa.2015.07.001.

Karimi M, Al-Maamari RS, Ayatollahi S, Mehranbod N. Wettability alteration and oil recovery by spontaneous imbibition of low salinity brine into carbonates: impact of $\mathrm{Mg}^{2+}, \mathrm{SO}_{4}{ }^{2-}$ and cationic surfactant. J Pet Sci Eng. 2016;147:560-9. https://doi.org/10.1016/j. petrol.2016.09.015.

Pal S, Mushtaq M, Banat F, et al. Review of surfactant-assisted chemical enhanced oil recovery for carbonate reservoirs: challenges and future perspectives. Pet Sci. 2018;15(1):77-102. https://doi. org/10.1007/s12182-017-0198-6.

Park H, Park Y, Lee Y, et al. Efficiency of enhanced oil recovery by injection of low- salinity water in barium- containing carbonate reservoirs. Pet Sci. 2018;15(4):772-82. https://doi.org/10.1007/ s12182-018-0244-z.

Puntervold T, Strand S, Ellouz R, Austad T. Modified seawater as a smart EOR fluid in chalk. J Pet Sci Eng. 2015;133:440-3. https:// doi.org/10.1016/j.petrol.2015.06.034.

Saidi AM. Reservoir engineering of fractured reservoirs: fundamental and practical aspects. Paris: Total Ed. Press; 1987.

Standnes DC, Austad T. Wettability alteration in chalk: 1. preparation of core material and oil properties. J Pet Sci Eng. 2000a;28(3):11121. https://doi.org/10.1016/S0920-4105(00)00083-8.

Standnes DC, Austad T. Wettability alteration in chalk: 2. mechanism for wettability alteration from oil-wet to water- wet using 
surfactants. J Pet Sci Eng. 2000b;28(3):123-43. https://doi. org/10.1016/S0920-4105(00)00084-X.

Strand S, Austad T, Puntervold T, Høgnesen EJ, Olsen M, Barstad SMF. "Smart water" for oil recovery from fractured limestone: a preliminary study. Energy and Fuels. 2008;22(5):3126-33. https ://doi.org/10.1021/ef800062n.

Strand S, Puntervold T, Austad T. Water based EOR from clastic oil reservoirs by wettability alteration: a review of chemical aspects. J Pet Sci Eng. 2016;146:1079-91. https://doi.org/10.1016/j.petro 1.2016.08.012.

Treiber L, Owens W. A laboratory evaluation of the wettability of fifty oil-producing reservoirs. SPE Journal. 1972;12(06):531-40. https ://doi.org/10.2118/3526-PA.
Yi Z, Sarma HK. Improving waterflood recovery efficiency in carbonate reservoirs through salinity variations and ionic exchanges: A promising low-cost" smart-waterflood" approach. In: Abu Dhabi International petroleum conference and exhibition, society of petroleum engineers; 2012. https://doi.org/10.2118/161631-MS.

Zahid A, Shapiro A, Stenby EH, Yan W. Managing injected water composition to improve oil recovery: a case study of North Sea chalk reservoirs. Energy Fuels. 2012;26(6):3407-15. https://doi. org/10.1021/ef2008979. 